2. The degree of damage is related to the dose and is not influenced by resistance of individual animals to the chemical. Identical doses produce almost identical lesions.

We have much pleasure in expressing thanks to the Council of the Imperial Cancer Research Fund for its generous help in providing laboratory and equipment for this work; to Messrs. Glaxo for supplies of ascorbic acid and of animals; to Mr. H. G. Crabtree for instruction on the chemical and physical properties of mustard gas; to Group Captain P. C. Livingston and Flight Lieutenant $H$. M. Walker for their invitation to continue the work and their whole-hearted co-operation.

\title{
REFERENCES
}

1. Livingston, P. C. and Walker, H. M.-Brit. Jl. Ophthal., p. 67, February, 1940.

2. Warthin, A. S., Weller, C. V. and Hermann, G. R.-Jl. Lab and Clin. Med., Vol. IV, p. 785, 1919.

\section{BOECK'S SARCOIDOSIS OF THE LACRYMAL GLAND}

BY

\author{
H. B. Stallakd \\ R.A.M.C.
}

THE terms lupus pernio, Besnier-Boeck's disease, Boeck's sarcoidosis, and Shaumann's benign lymphogranuloma are synonyms for a disorder of parts of the reticulo-endothelial system characterised by nodular lesions composed of a central mass of endothelial cells surrounded by a fringe of lymphocytes and, very rarely, a giant cell of the Langhans type. Caseation is never seen in these lesions, tubercle bacilli are not evident in specially stained sections, and inoculation of material from these nodules into a guinea-pig gives a negative result.

Some authors have suggested that this disease and uveoparotitis are a tuberculous or so-called para-tuberculous manifestation, but there seems to be no definite clinical or experimental evidence to support this conception. Syphilis has also been blamed, but without good reason. However, the cause of this disease remains so far unknown. On histological grounds it appears to belong to a group of disorders of the reticulo-endothelial system in which may be included uveoparotitis (Heerfordt), lymphadenoma (Hodgkin), 
and certain other allied conditions. Uveoparotitis and Boeck's sarcoidosis run a chronic benign course, but terminate, except for the ocular sequelae in some cases, in complete recovery after a number of years, whereas lymphadenoma is malignant and fatal.

The lesions of Boeck's sarcoidosis are found in the lymph nodes, spleen, skin, lungs, parotid and lacrymal glands, bones of the fingers, the conjunctiva, cornea, the uveal tract, and more rarely in the optic nerve, chiasma, breasts, testicles, upper air passages, and hypophysis. All these tissues may not be affected during the course of the disease, which manifests itself in some only. Healing may occur in one group of structures and on remission the disease appears in another. Lymphadenopathy is evident in all cases at some stage and may be generalised or affect only one group of lymph nodes, which become enlarged, discrete, mobile, painless, and insensitive. Splenomegaly is also apparent in a number of cases. The skin lesions are bizarre. For descriptive purposes they may be grouped as follows :-

(1) Miliary lupoid.-(a) Small reddish-brown hemispherical papules and nodules, the size of a corn seed, soft, and with a smooth surface, which shows light desquamation and hyperkeratosis in some cases. These may become flattened, spread out, depressed in the centre, and ultimately cicatrized atrophic plaques. (b) The nodular variety is rarer, and the lesions are larger than those just described, some being $5 \mathrm{~cm}$. in diameter during the stage of eruption. They effect first the cheeks and are also found on the nose, shoulders, extensor aspects of the upper extremities, and the knees. They are smooth, slightly elevated, and bluishred. The florid stage may last twenty years and the lesions become violaceous and have a telangiectatic surface. During involution the centres become flattened and depressed, the margins telangiectatic and pigmented, and the spots annular.

(2). Lupus pernio.-The skin of the cheeks, nose and sometimes the lobes of the ears and the skin of the fingers over an associated osseous lesion is diffusely infiltrated, with a sharp border and a burnished surface.

(3) Angio-lupoid.-Soft infiltrated violet-red plaques showing many telangiectases are found on the side of the root of the nose in middle-aged females.

(4) Erythrodermic sarcoidique.-Large superficial serpiginous red areas affect the front of the legs and thighs.

The lung fields on X-ray examination show diffuse mottling resembling miliary tuberculosis but coarser and less regularly disposed. The mediastinal and hilar lymph-nodes are enlarged, and in some cases there are basal crepitations and cough. There may be enlargement of the lacrymal and parotid glands, the latter 
being associated with facial palsy. The phalanges of the hands and feet show in some instances painful fusiform swellings, which radiographically appear as a lace-like network with small areas of rarefaction surrounded by a zone of increased density. These osseous lesions may lead to mutilation or heal with some deformity of the nail when the terminal phalanx is affected. The ocular manifestations associated with Boeck's sarcoidosis are not common. Blegvad (1931) states that iridocyclitis occurs in 10 per cent. of the cases, but it seems that the incidence may be less than this, between 5 and 10 per cent. Blegvad (1931), Schoeppe (1920), Seefelder (1932), and Coppez and Dujardin (1938) have noted multiple translucent yellowish projecting follicles in the palpebral conjunctiva and upper fornix, some of which formed a conglomerated mass resembling a fungating Meibomian granuloma. Stumpke (1913) has seen keratitis, consisting of small superficial corneal opacities, associated with the cutaneous lesions of Boeck's sarcoidosis, and this complication also occurred in Stallard and Tait's case. Iritis, iridocyclitis, and uveitis have been noted by a number of authors, and Bering (1910) and Coppez and Dujardin (1938) and Osterberg (1939) have reported greyish nodules in the iris. These bear some resemblance to tuberculous iritis, they are more frequently disposed at or near the periphery of the iris and more rarely near the pupil margin. They may disappear and reappear with remissions of the disease. The iritis is relatively painless. Some of the cases of iridocyclitis recover and have a reasonable degree of vision, but others end in atrophy of the globe; this disastrous sequel has been recorded by Habermann (1927), Schoeppe (1920), Mylius (1928), Fraenkel (1922) and Stallard and Tait (1939).

Reis and Rothfeld (1931) have described the case of a girl, aged 17 years, who suffered from Boeck's sarcoidosis and had bilateral papilloedema and subsequent optic atrophy. Necropsy revealed well defined follicular infiltration of the left optic nerve, left papilla and chiasma with endothelial cells which extended to the cerebral peduncle and left temporal lobe. There were no areas of caseation, no necrosis, and no giant cells. Meningeal symptoms and signs and right hemicrania were present in a patient whose case is reported by Coppez and Dujardin (1938). These authors comment also on the slow course of Boeck's sarcoidosis and the exacerbation of symptoms at the menses. Anaemia is mild or absent, a moderate mononucleosis and eosinophilia and an increase of plasma globulin being present in some cases.

Stallard and Tait described the case of a woman aged 44 years, who at the age of 38 years had a painless lump in her right breast, lymphadenopathy of the axillary lymph nodes on the same side 
and in the left anterior and posterior triangles of the neck. One year later she developed bilateral iridocyclitis and keratitis, complicated cataract and lowered intra-ocular pressure which terminated in phthisis bulbi of the left eye. Excess of fluid became evident in both knee joints and one year later left parotitis and left facial paresis occurred. Radiographs of the chest suggested healed sarcoidosis lesions in the right lung. Four years after the onset of this illness she developed the classical features of myxoedema. The breast and cervical lymph nodes lesions showed the histological picture of Boeck's sarcoidosis.

\section{Case Report}

D. W., a married woman, aged 45 years, was admitted to the eye ward at St. Bartholomew's Hospital, on July 18, 1939. For six months she had noticed a swelling in the upper and outer angle of the right orbit. This was increasing in size. The right eye was displaced downwards, forwards and inwards. The swelling about the size of a damson occupied the position of the lacrymal gland : was slightly nodular : of firm elastic consistence and the skin was mobile over it. It was attached to the orbital tissues but not to the bone forming the roof of the orbit.

General examination.-The patient was obese, no enlargement of the lymph nodes nor of the liver and spleen could be detected on palpation. Over the right axillary fold there was a pigmented papilloma $\frac{1}{3}$ inch in diameter and there were some bluish patches of discoloration in the skin of the forearms, but there were no cutaneous lesions characteristic of Boeck's sarcoidosis.

Past history.-In August, 1932, the patient suffered from lassitude, night sweating and swellings behind the right ear and on both sides of the neck. During the previous six months these symptoms became worse and her weight fell from 14 stone $6 \mathrm{lbs}$. to 13 stone $3 \mathrm{lbs}$. She was admitted to St. Bartholomew's Hospital on February 8, 1933.

General examination.-She was stout and pale. Enlarged discrete, firm, lymph nodes not adherent to the skin were found behind the right auricle, in the anterior and posterior triangles on both sides of the neck and in the axillae. The spleen was enlarged and extended to within two fingers' breadth of the umbilicus and the liver was palpable one finger's breadth below the costal margin.

Radiographs of the chest showed enlarged shadows in the hilus on both sides and posterior mediastinal opacities.

The blood count was, red blood count, 5,400,000. Hb. 58 per cent., white blood count 5,600 (polymorphonuclear leucocytes 
39.5 per cent., lymphocytes 59 per cent., eosinophils 1 per cent., and large mononuclear leucocytes 0.5 per cent.).

Biopsy of a lymph node showed " evidence of chronic inflammation but not lymphadenoma."

$\mathrm{X}$-ray treatment to the thorax and upper abdomen caused the patient to feel ill and during its course bronchitis occurred.

On April 1, 1933, she was discharged from the hospital. The cervical lymph nodes were considerably reduced in size and the spleen was also smaller.

On September 9, 1933, she was re-admitted to St. Bartholomew's Hospital. Enlarged lymph nodes were evident at the following sites : right and left pre-auricular, occipital, below left ear and behind angle of jaw, right anterior triangle of neck, right and left supraclavicular and right and left inguinal. The spleen was palpable one finger's breadth below the costal margin. Deafness and tinnitus in the right ear were due to Eustachian obstruction.

The blood count was : r.b.c., $4,730,000 ; \mathrm{Hb}: 86$ per cent.: C.1, 0.91 per cent.: w.b.c., 6,300 (polymorphonuclear leucocytes 69.5 per cent., large lymphocytes 1.5 per cent., small lymphocytes 21 per cent., large mononuclear leucocytes 3.5 per cent., and eosinophils 2 per cent.).

A further course of X-ray treatment was given and the patient discharged from hospital. She remained well until the lacrymal gland swelling appeared in February, 1939.

Operation.- July 23, 1939. A curved incision was made corresponding with and $0.5 \mathrm{~cm}$. below the temporal half of the right supra-orbital margin and continued downwards and outwards to the upper edge of the lateral palpebral ligament. The lower edge of the incision was undermined and the flap thus formed was retracted downwards and nasalwards. The orbicularis fibres were split and retracted so as to expose the swelling occupying the lacrymal gland. The swelling was about the shape and size of a damson plum $(2.5 \times 1.75 \mathrm{~cm}$.$) , apparently encapsuled and of$ firm elastic consistence. It was removed without difficulty or complication and the residual space was drained with a fine piece of split rubber for 48 hours. The edges of the orbicularis muscle were united with two catgut sutures and the skin closed with interrupted silk sutures.

Post-operative healing was uneventful.

Pathological report.- The neoplasm is composed of masses of endothelioid cells irregularly arranged. Between some of the cells there are collagen material and extravasated red blood corpuscles. The endothelioid cells show variations in shape and size, and mitotic figures are evident in some of them. Around these 


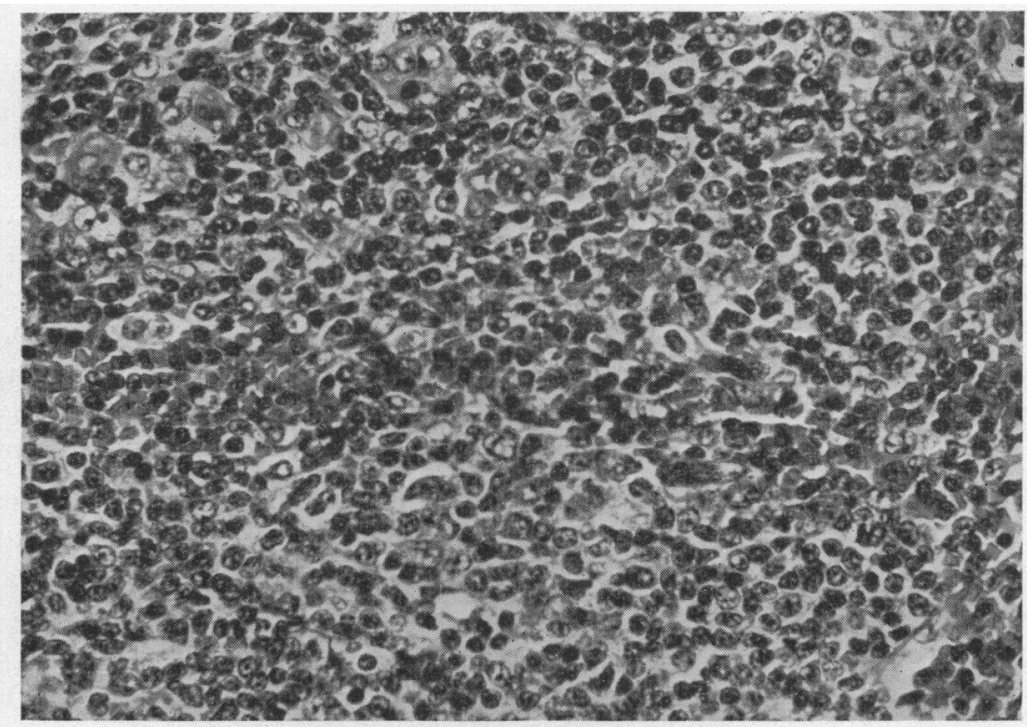

Microphotograph. High power, $\times 500$. Section of sarcoid tissue in lacrymal gland. Endothelioid cells, lyphocytes and intercellular collagen are to be seen.

cellular masses and at the periphery of the gland are aggregations of lymphocytes. Islands of compressed acini are scattered throughout the neoplasm and the blood vessels show hyaline degeneration in the tunica media and endothelial proliferation in the intima. Some normal lacrymal gland tissue is also present. There were no areas of caseation and no tubercle bacilli.

\section{Commentary}

From the clinical features in 1932 and 1933 and the histological appearance of the excised lymph node it was evident that this patient was suffering from a disorder of the reticulo-endothelial system. Neither the microscopic examination at this time nor the subsequent clinical history suggested lymphadenoma.

Her symptoms and signs subsided after about 18 months and she remained well until the recurrence in the right lacrymal gland in 1939. The histological features of the excised lacrymal gland swelling resembled those seen in Boeck's sarcoidosis. In this disorder all the tissues of the reticulo-endothelial system are not necessarily involved and although lymphadenopathy is evident in all cases at some stage in the disease, one group of nodes may be affected at one time and another later. In this case 
lymphadenopathy, splenomegaly, mediastinal changes and later involvement of the right lacrymal gland were the chief clinical features.

\title{
LITERATURE
}

BERING, F-Derm. Z., Vol. XVII, p..404, 1910.

Blegvad, O.-Acta Ophthal. Kbh., Vol. IX, p. 180, 1931.

BoEck, C.-Jl. Cutan. Dis., Vol.:XVII, p. 543, 1899 ; Arch. Derm. Syph.

Wien., Vol. LXXIII, p. 301, 1905; Ibid Vol. CXXI, p. 707, 1915.

Coppez, H. and DujaRdin, B.-Arch. Ophtal., Vol. II, p. 497, 1938.

FrAENKEL, E.-Beitr. Klin. Tuberk., Vol. L, p. 441, 1922.

HABERMAN , R.-Zentralbl. Haut. u. Geschlkr., Vol. XXIV, p. 592, 1927.

MEYER, F. W.-Klin. Monatsbl.f. Augenheilk., Vol. C, p. 377, 1938.

MYLIUS, K.-Zeitschr.f. Augenheilk., Vol. LXV, p. 71, 1928.

OSTerberg.-Brit. Jl. Ophthal., Vol. XXII, p. 145, 1939.

Pautrier, L. M.-Ann. Derm. Syph., Vol. ViI, p. 433, 1936.

REIS, W. and RothField, J.-v. Graefe's Archiv.f. Ophthal., Vol. CXXVI, p. $357,1931$.

Sсное Р Р, H.-Klin. Monatsbl. f. Augenheilk., Vol. LXV, p. 812, 1920.

SCHU MAEKER, G.-Münch. med. Woschr., Vol. LVI, p. 2664, 1909.

SEEFELder, R.-Arch. $f$. Augenheilk., Vol. CV, p. 664, 1932.

StallaRD, H. B and TAIT, C. B. V.-Lancet, p. 440, February, 1939.

STUMPKE, G.-Derm. Z., Vol. XX, p. 199, 1913.

\section{A CASE OF CHRONIC GRANULOMA OF THE LACRYMAL SAC}

BY

\author{
H. B. Stallard
}

R.A.M.C.

THE following case of a swelling in the lacrymal sac is of some interest from the point of view of differential diagnosis. It also illustrates the necessity for a thorough examination in such cases. In this instance radiography played a very important part in determining the cause of the swelling which was eventually confirmed by the microscope.

R. H., aged 68 years, was referred to the Radium Institute in March, 1939, on account of a swelling of the right inner canthus which was believed by his ophthalmic surgeon to be a malignant neoplasm and for which he considered radiotherapy was necessary. Mr. Roy Ward invited me to see this patient.

For 33 years the patient had suffered from right dacryocystitis and for 3 years there had been a swelling at the right inner canthus which was increasing in size.

The inner canthus was enlarged and drawn downwards and nasalwards. A firm elastic swelling $2.5 \mathrm{~cm}$. long by $1.5 \mathrm{~cm}$. wide, occupied the site of the lacrymal sac and the caruncle and it was 